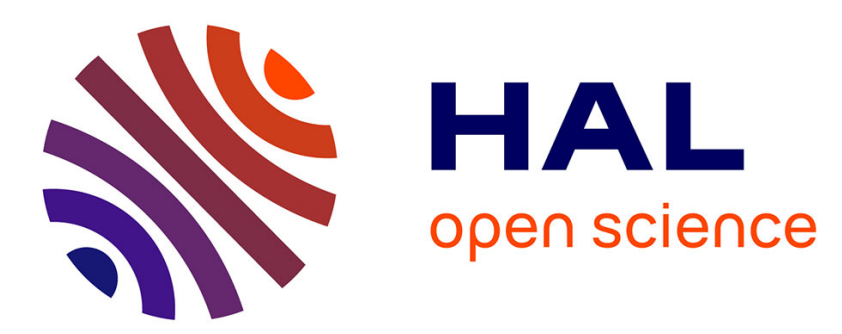

\title{
Engineering porous and compact two-dimensional nanoarchitectures on surfaces taking advantage of bisterpyridine-derivatives self-assembly
}

\author{
Fabien Silly, Yann Kervella, Bruno Jousselme
}

\section{- To cite this version:}

Fabien Silly, Yann Kervella, Bruno Jousselme. Engineering porous and compact two-dimensional nanoarchitectures on surfaces taking advantage of bisterpyridine-derivatives self-assembly. RSC Advances, 2015, 5, pp.101740. 10.1039/c5ra22117j . cea-01349731

HAL Id: cea-01349731

https://hal-cea.archives-ouvertes.fr/cea-01349731

Submitted on 28 Jul 2016

HAL is a multi-disciplinary open access archive for the deposit and dissemination of scientific research documents, whether they are published or not. The documents may come from teaching and research institutions in France or abroad, or from public or private research centers.
L'archive ouverte pluridisciplinaire HAL, est destinée au dépôt et à la diffusion de documents scientifiques de niveau recherche, publiés ou non, émanant des établissements d'enseignement et de recherche français ou étrangers, des laboratoires publics ou privés. 


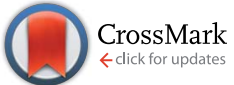

Cite this: RSC Adv., 2015, 5, 101740

Received 22nd October 2015 Accepted 19th November 2015

DOI: $10.1039 / c 5 r a 22117 j$

www.rsc.org/advances

\section{Engineering porous and compact two-dimensional nanoarchitectures on surfaces taking advantage of bisterpyridine-derivatives self-assembly $\dagger$}

\author{
Fabien Silly, ${ }^{\text {*a }}$ Yann Kervella ${ }^{\mathrm{b}}$ and Bruno Jousselme ${ }^{\mathrm{bc}}$
}

The self-assembly of two bis-terpyridine derivatives is experimentally investigated at the nanometer scale. Scanning tunneling microscopy (STM) reveals that two-dimensional compact and porous nanoarchitectures can be engineered by changing the length of terpyridine spacer; i.e. a benzene ring or a quaterthiophene (4T) unit. In both cases the molecular nanoarchitecture appears to be stabilized by double hydrogen-bonds between molecular terpyridine groups. The STM images suggest however that terpyridine groups adopt different conformations, s-cis and s-trans as well as s-trans and s-trans conformations, in the two self-assembled organic layers.

\section{Introduction}

Bottom-up engineering novel organic nanoarchitecture of functionalised molecules ${ }^{\mathbf{1 - 2 1}}$ is attracting enormous research interest. The local as well as the long range arrangement of organic or hybrid building blocks can have a drastic influence on the electronic properties of the resulting thin film. ${ }^{22,23}$ Hydrogen-bonding is an appealing interaction to drive molecular self-assembly due to the strength, the high selectivity and the directionality of this binding. ${ }^{24-33}$ Pyridine units are a specially interesting substituent to drive molecular selfassembly. ${ }^{34,35}$ This group allows the formation of double hydrogen-bonds $(\mathrm{C}-\mathrm{H} \cdots \mathrm{N})$ between neighboring molecules. Numerous pyridine-based molecular building blocks have been synthesized ${ }^{36,37}$ and various nanoarchitectures have been engineered using these compounds..$^{36,38-41}$ The mission of terpyridine group of the functionalised compound is usually to drive molecular assembly whereas the molecular central part is carrying the specific electronic or geometric properties of the building block. A compound composed of terpyridine subunits connected to a spacer only via $\mathrm{C}-\mathrm{C}$ single bonds (Fig. 1) appears therefore to be a promising building block to engineer novel nanoarchitectures. However changing the length, dimension or the nature of molecular spacer can not only affect molecular properties but can also drastically affect molecular self-

aTITANS, SPEC, CEA, CNRS, Université Paris-Saclay, CEA Saclay, F-91191 Gif sur Yvette, France. E-mail: fabien.silly@cea.fr; Fax: +33 o 169088446; Tel: +33 o 169088019

${ }^{b}$ CEA Grenoble INAC/SPrAM UMR 5819 CEA - CNRS - Univ. J. Fourier-Grenoble 1, LEMOH, 17 Rue des Martyrs, 38054 Grenoble Cedex 9, France

'LICSEN, NIMBE, CEA, CNRS, Université Paris-Saclay, CEA Saclay, F-91191 Gif sur Yvette, France

$\dagger$ Electronic supplementary information (ESI) available. See DOI: $10.1039 / \mathrm{c} 5 \mathrm{ra} 22117 \mathrm{j}$

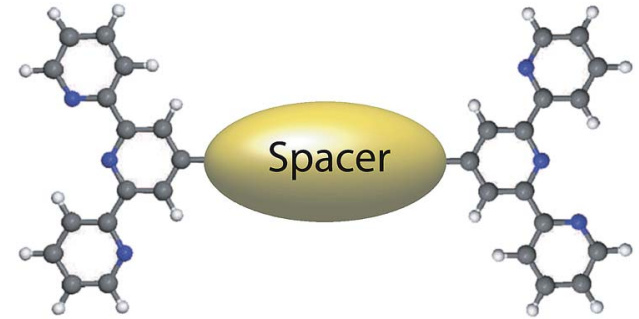

Fig. 1 Schematic representation of bisterpyridine molecular building block.

assembly, especially when localized molecular groups can adopt different conformations.

In this paper, we investigate the self-assembly of two bisterpyridine molecular derivatives. The two compounds have different terpyridine chain-like spacers. Scanning tunneling microscopy (STM) at the 1-phenyloctane/graphite interface reveals that the molecules can self-assemble into compact and porous two-dimensional chiral nanoarchitectures depending of the conformation of the bisterpyridine spacer.

\section{Experimental}

Solutions of phenylene-bisterpy (Fig. 2a) (Sigma-Aldrich) and 4T-bisterpy (Fig. 2b) in 1-phenyloctane (98\%, Aldrich) were prepared (concentration range of $10^{-5} \mathrm{~mol} \mathrm{~L}^{-1}$ ). A droplet of these solutions was then deposited on a graphite substrate. STM imaging of the samples was performed at the liquid/solid interface ${ }^{\mathbf{4 2 - 4 4}}$ using a Pico-SPM (Molecular Imaging, Agilent Technology) scanning tunneling microscope. Cut Pt/Ir tips were used to obtain constant current images at room temperature with a bias voltage applied to the sample. STM images were processed and analyzed using the application FabViewer. ${ }^{45}$ 


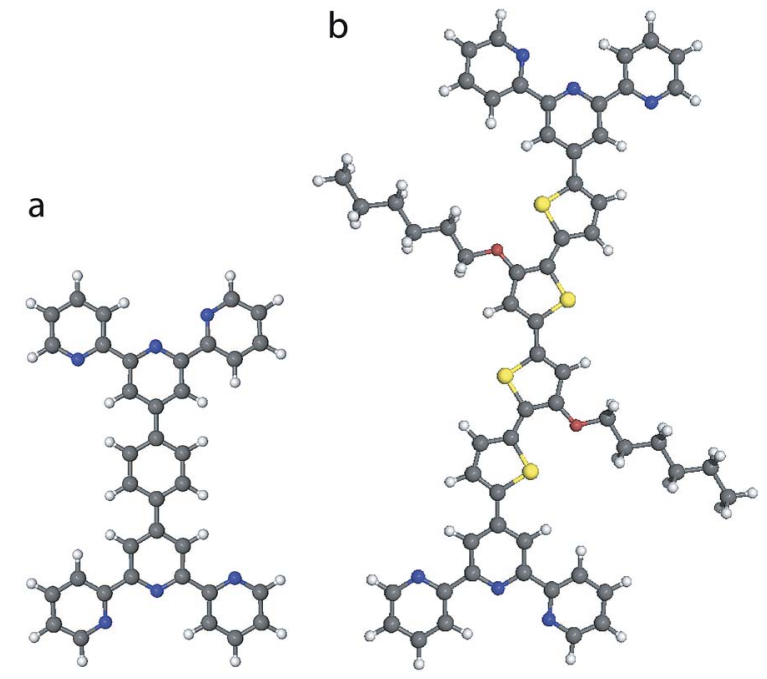

Fig. 2 Schematic representation of (a) $4^{\prime}, 4^{\prime \prime \prime \prime}-(1,4$-phenylene) bis $\left(2,2^{\prime}: 6^{\prime}, 2^{\prime \prime}\right.$-terpyridine $)\left(\mathrm{C}_{36} \mathrm{H}_{24} \mathrm{~N}_{6}\right)$ and (b) $4^{\prime}-\left(3^{\prime}, 4^{\prime \prime}\right.$-dihexyloxy$5,2^{\prime}: 5^{\prime}, 2^{\prime \prime}: 5^{\prime \prime}, 2^{\prime \prime \prime}$ - quaterthien-2, $5^{\prime \prime \prime}$-diyl)-bis (2, $2^{\prime}: 6^{\prime}, 2^{\prime \prime}$-terpyridine) (4Tbisterpy) molecule $\left(\mathrm{C}_{58} \mathrm{H}_{52} \mathrm{~N}_{6} \mathrm{O}_{2} \mathrm{~S}_{4}\right)$. Carbon atoms are gray, oxygen atoms are red, nitrogen atoms are blue, hydrogen atoms are white, and sulfur atoms are yellow respectively.

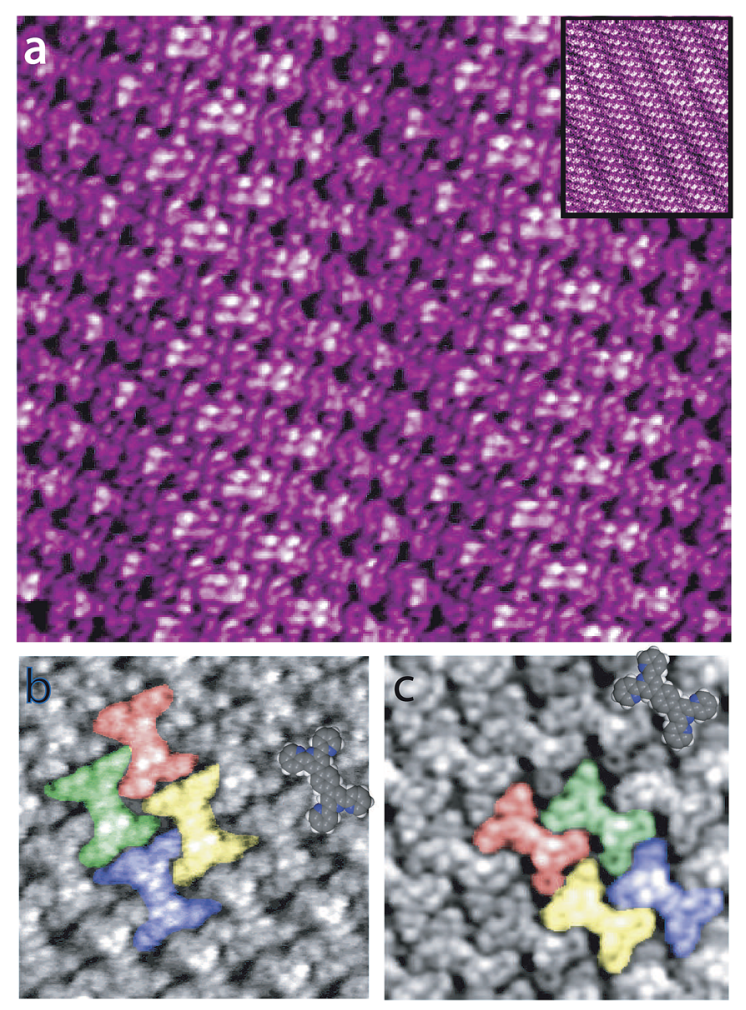

Fig. 3 Large scale STM images of phenylene-bisterpy on graphite, (a) $15 \times 13 \mathrm{~nm}^{2} ; V_{\mathrm{s}}=0.35 \mathrm{~V}, l_{\mathrm{t}}=9 \mathrm{pA}$; (inset) $35 \times 30 \mathrm{~nm}^{2} ; V_{\mathrm{s}}=0.4 \mathrm{~V}, l_{\mathrm{t}}=$ $10 \mathrm{pA}$. The two enantiomeric domains are presented in the highresolution STM images: (b) $6 \times 6 \mathrm{~nm}^{2} ; V_{\mathrm{s}}=1.3 \mathrm{~V}, \mathrm{I}_{\mathrm{t}}=15 \mathrm{pA}$. (c) $6 \times$ $6 \mathrm{~nm}^{2} ; V_{\mathrm{s}}=0.6 \mathrm{~V}, I_{\mathrm{t}}=10 \mathrm{pA}$. Molecules composing the unit cell have been colored in red, green, blue and yellow colors in (b and $c$ ). Molecule model is superimposed to the STM images in (b and c).
Table 1 The lengths (in $\AA$ ) of the two lattice vectors $\left(A_{1}, A_{2}\right)$ and the angle $\theta$ between them (in degrees) for phenylene-bisterpy and 4T-bisterpy self-assembled nanoarchitectures. The difference in the orientations of the two molecules within the cell are shown by the angle $\tau$ (also in degrees)

\begin{tabular}{|c|c|c|}
\hline Molecule & Phenylene-bisterpy & 4T-bisterpy \\
\hline Arrangement & Close-packed & Porous \\
\hline$A_{1}(\AA)$ & 14 & 25 \\
\hline$A_{2}(\AA)$ & 20 & 17 \\
\hline$\Theta$ & $65^{\circ}$ & $58^{\circ}$ \\
\hline$\tau$ & $0^{\circ}$ & $0^{\circ}$ \\
\hline
\end{tabular}
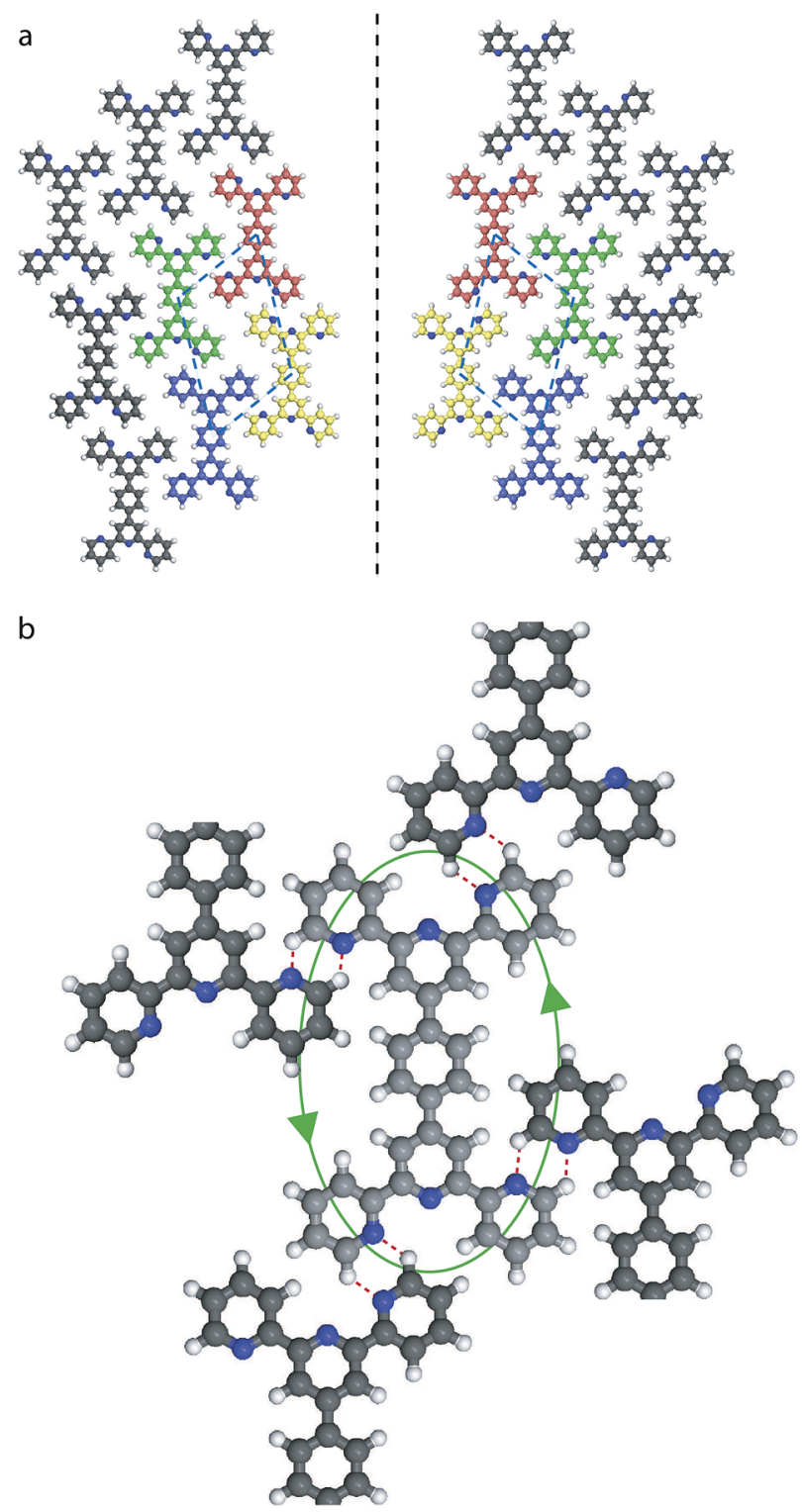

Fig. 4 (a) Model of phenylene-bisterpy self-assembly on graphite. Molecules composing the unit cell (dashed lines) have been colored in red, green, blue and yellow colors. (b) Scheme of the terpyridine bounding. $\mathrm{N} \cdots \mathrm{H}-\mathrm{C}$ bonds are represented by dotted red lines. 


\section{Results}

\subsection{Phenylene-bisterpy}

The STM image presented in Fig. 3a shows that phenylenebisterpy molecules self-assemble into a large scale nanoarchitecture at the 1-phenyloctane/graphite interface. Fig. 3a also reveals that a Moiré pattern (parallel stripes) appears in the STM image when the organic layer is formed on the graphite surface. High resolution STM images of the phenylene-bisterpy nanoarchitectures are presented in Fig. $3 \mathrm{~b}$ and c. The images are showing that the phenylene-bisterpy assembly is chiral. The two enantiomeric structures are presented in Fig. $3 \mathrm{~b}$ and c. The four neighboring molecules forming the chiral network unit cell have been colored in yellow, red, blue and green as a guide for the eyes. The scheme of the molecule is also superimposed to the STM images in Fig. 3b and c. The molecules are arranged parallel to each other in the organic layer. The network unit cell of this close-packed nanoarchitecture is a parallelogram with $2.0 \mathrm{~nm}$ and $1.4 \mathrm{~nm}$ unit cell constants and an angle of $\sim 65^{\circ}$ between the axes, Table 1 . The model of phenylene-bisterpy molecules self-assembly is presented in Fig. 4.

\subsection{T-bisterpy}

The Fig. 5a shows an STM image of the 4T-bisterpy selfassembly. The 4T-bisterpy molecules form a porous

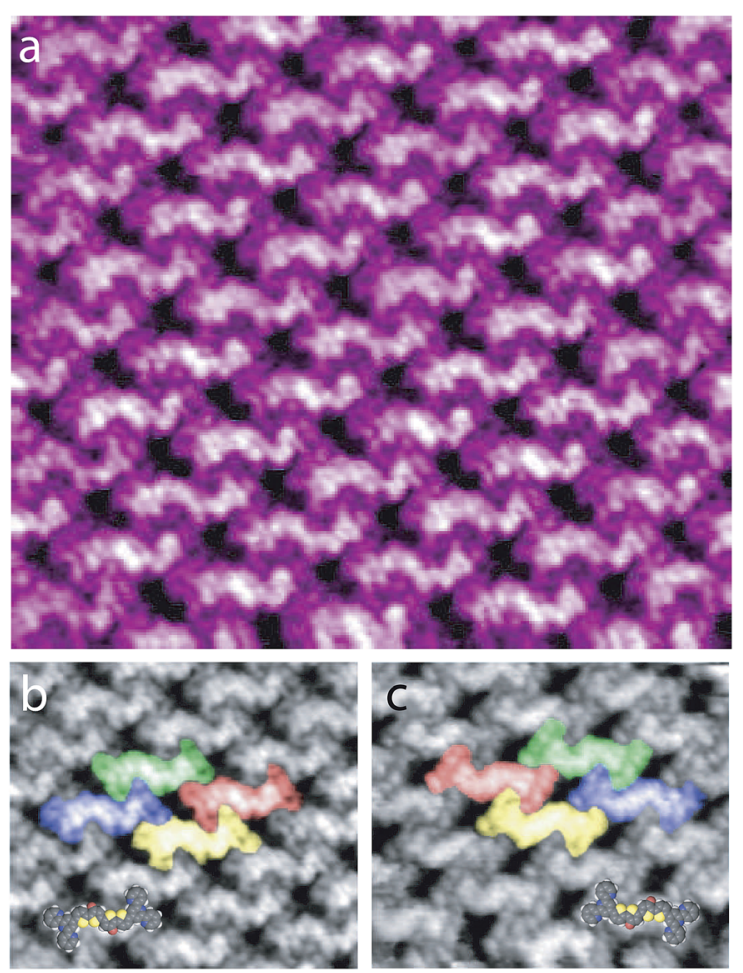

Fig. 5 (a) Large scale STM image of 4T-bisterpy self-assembled nanoarchitecture on graphite, $15 \times 13 \mathrm{~nm}^{2} ; V_{\mathrm{s}}=0.40 \mathrm{~V}, I_{\mathrm{t}}=9 \mathrm{pA}$. The two enantiomeric domains are presented in the high-resolution STM images $\left(b\right.$ and $\mathrm{c}$ ), $9 \times 8 \mathrm{~nm}^{2}, V_{\mathrm{s}}=0.40 \mathrm{~V}, l_{\mathrm{t}}=9 \mathrm{pA}$. Molecules composing the unit cell have been colored in red, green, blue and yellow colors in (b and c). Molecule model is superimposed to the STM images in (b and $c)$.

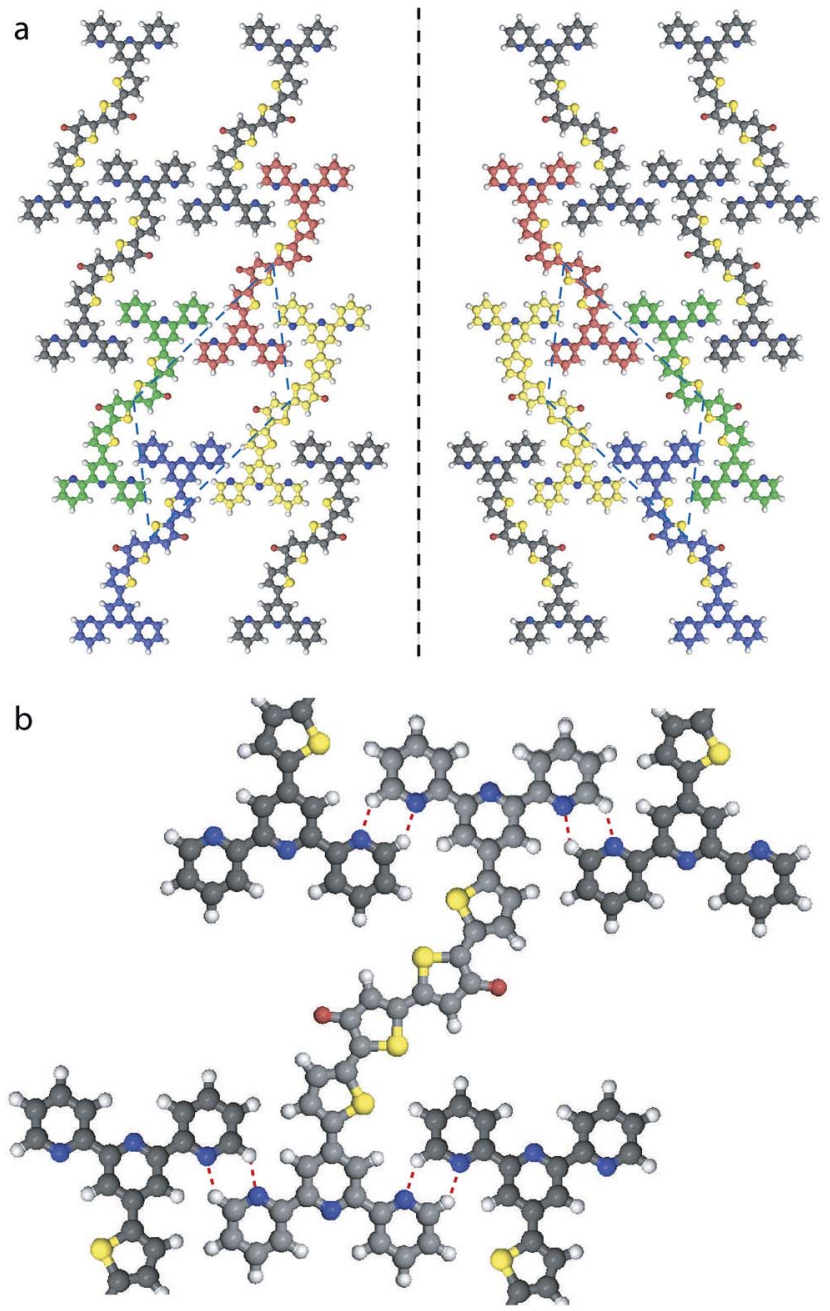

Fig. 6 (a) Model of 4T-bisterpy self-assembly on graphite. Molecules composing the unit cell (dashed lines) have been colored in red, green, blue and yellow colors. (b) Scheme of the terpyridine bounding. $\mathrm{N} \cdots \mathrm{H}-\mathrm{C}$ bonds are represented by dotted red lines.

nanoarchitecture at the 1-phenyloctane/graphite interface. The molecular network is chiral. The two molecular enantiomers can be observed in Fig. 5b and c. The network unit cell of this chiral arrangement is a parallelogram with $\sim 25 \AA$ and $\sim 17 \AA$ unit cell constants and an angle of $\sim 58^{\circ}$ between the axes. The STM images of individual molecule reveal not only that the molecular quatertiophene backbone appears brighter than the terpyridine groups but also that the molecules adopt a "S"-shape in the organic layer, i.e. the molecular quatertiophene backbone is not straight. The model of the molecular nanoarchitecture is presented in Fig. 6 . The chiral domains are based on one single enantiomer, as observed in the STM images (Fig. 5).

\section{Discussion}

STM images show that both phenylene-bisterpy and 4T-bisterpy molecules self-assemble into two-dimensional chiral nanoarchitectures on the graphite surface. These two molecules 
differ by the nature and structure of their terpyridine spacer. The experimental data reveal that the structure based on phenylene-bisterpy molecules is compact whereas the structure based on 4T-bisterpy molecules is porous. The analysis of molecular arrangement suggests that the two 2D nanoarchitectures appear to be both stabilized by double $\mathrm{N} \cdots \mathrm{H}-\mathrm{C}$ hydrogen-bonds between molecular pyridine rings of neighboring molecules, as highlighted by red dotted lines in Fig. 4b and $6 \mathrm{~b}$. The orientation of molecular pyridine rings appears to be however different in the phenylene and 4T-bisterpy nanoarchitectures. The two peripheral pyridine rings of the phenylene-bisterpy groups adopt a s-trans and a s-cis conformation in the self-assembled nanoarchitecture. The four pyridine groups rotate clockwise in the chiral domain in Fig. $4 \mathrm{a}$ (left) and rotate anti-clockwise in enantiomeric chiral domain in Fig. 4a (right). The anti-clockwise rotation is highlighted by a green curve as a guide for the eyes in Fig. $4 \mathrm{~b}$. In comparison the four peripheral pyridine rings of the $4 \mathrm{~T}$-bisterpy groups only adopt a s-trans conformation in the self-assembled nanoarchitecture.

The phenylene-bisterpy nanoarchitecture is a close-packed $\mathrm{H}$-bonded structure, i.e. this compact assembly also favors intermolecular interactions between neighboring molecules. In contrast the 4T-bisterpy nanoarchitectures is a porous structure. The STM images show that 4T-bisterpy backbone adopts an "S"-conformation in the molecular arrangement. This molecular conformation also maximizes the compactness of the organic layer in comparison with a backbone straight configuration (see Fig. 2a).

\section{Conclusion}

In this paper we investigated the self-assembly of bisterpyridine compounds on graphite. By changing the length and the nature of the molecular backbone separating the terpyridine groups we succeeded in engineering close-packed as well as porous two-dimensional nanoarchitectures. STM reveals that molecular pyridine groups can adopt s-cis and s-trans as well as s-trans and s-trans configurations in organic nanoarchitectures, respectively. The two organic films are however both stabilized by double hydrogen-bonds between pyridine groups. The high conformational flexibility of these compounds opens up new opportunities for engineering novel 2D organic structures for applications in organic electronic. ${ }^{46,47}$

\section{Acknowledgements}

The research leading to these results has received funding from the European Research Council under the European Union's Seventh Framework Programme (FP7/2007-2013)/ERC grant agreement no. 259297.

\section{References}

1 L. Bartels, Nat. Chem., 2010, 2, 87-95.

2 J. A. A. W. Elemans, S. Lei and S. de Feyter, Angew. Chem., Int. Ed., 2009, 48, 7298-7332.
3 H. Liang, Y. He, Y. Ye, X. Xu, F. Cheng, W. Sun, X. Shao, Y. Wang, J. Li and K. Wu, Coord. Chem. Rev., 2009, 253, 2959-2979.

4 B. Roy, P. Bairi and A. K. Nandi, RSC Adv., 2013, 4, 1708-1734.

5 D. Wang, L. Wan and C. Bai, Mater. Sci. Eng., R, 2010, 70, 169-187.

6 Y. Yang and C. Wang, Chem. Soc. Rev., 2009, 38, 2576.

7 J. Mao, H. Zhang, Y. Jiang, Y. Pan, M. Gao, W. Xiao and H.-J. Gao, J. Am. Chem. Soc., 2009, 131, 14136-14137.

8 G. Pawin, K. L. Wong, K.-Y. Kwon and L. Bartels, Science, 2006, 313, 961-962.

9 Q. H. Wang and M. C. Hersam, Nat. Chem., 2009, 1, 206-211. 10 H. Maeda, Bull. Chem. Soc. Jpn., 2013, 86, 1359-1399.

11 B. Yang, Y. Wang, H. Cun, S. Du, M. Xu, Y. Wang, K.-H. Ernst and H.-J. Gao, J. Am. Chem. Soc., 2010, 132, 10440-10444.

12 A. Amrous, F. Bocquet, L. Nony, F. Para, C. Loppacher, S. Lamare, F. Palmino, F. Cherioux, D. Z. Gao, F. F. Canova, M. B. Watkins and A. L. Shluger, Adv. Mater. Interfaces, 2014, 1, 1400414.

13 Y. He, Y. Zhang, I.-P. Hong, F. Cheng, X. Zhou, Q. Shen, J. Li, Y. Wang, J. Jiang and K. Wu, Nanoscale, 2014, 6, 1077910783.

14 S. Uemura, M. Aono, K. Sakata, T. Komatsu and M. Kunitake, J. Phys. Chem. C, 2013, 117, 24815-24821.

15 R. Wu, L. Yan, Y. Zhang, J. Ren, D. Bao, H. Zhang, Y. Wang, S. Du, Q. Huan and H.-J. Gao, J. Phys. Chem. C, 2015, 119, 8208-8212.

16 Y. Kikkawa, M. Ishitsuka, A. Kashiwada, S. Tsuzuki and K. Hiratani, Chem. Commun., 2014, 50, 13146-13149.

17 H. Wu, K. Sotthewes, P. M. Schön, G. J. Vancso and H. J. W. Zandvliet, RSC Adv., 2015, 5, 42069-42074.

18 S. Yasuda, A. Furuya and K. Murakoshi, RSC Adv., 2014, 4, 58567-58572.

19 Y. Fan, L. Cheng, C. Liu, Y. Xie, W. Liu, Y. Li, X. Li, Y. Li and X. Fan, RSC Adv., 2014, 4, 52245-52249.

20 Z. Yin, G. Zhang, T. Phoenix, S. Zheng and J. C. Fettinger, RSC Adv., 2015, 5, 36156-36166.

21 J. Xue, K. Deng, B. Liu, W. Duan, Q. Zeng and C. Wang, RSC Adv., 2015, 5, 39291-39294.

22 J. Hieulle and F. Silly, J. Mater. Chem. C, 2013, 1, 4536-4539. 23 A. O. Gusev, A. Taleb, F. Silly, F. Charra and M.-P. Pileni, Adv. Mater., 2000, 12, 1583-1587.

24 S. Yagai, Y. Goto, X. Lin, T. Karatsu, A. Kitamura, D. Kuzuhara, H. Yamada, Y. Kikkawa, A. Saeki and S. Seki, Angew. Chem., Int. Ed., 2012, 51, 6643-6647.

25 J. V. Barth, J. Weckesser, C. Cai, P. Günter, L. Bürgi, O. Jeandupeux and K. Kern, Angew. Chem., Int. Ed., 2000, 39, 1230-1234.

26 M. Mura, F. Silly, G. A. D. Briggs, M. R. Castell and L. N. Kantorovich, J. Phys. Chem. C, 2009, 113, 21840-21848.

27 J. V. Barth, Annu. Rev. Phys. Chem., 2007, 58, 375-407.

28 M. Mura, X. Sun, F. Silly, H. T. Jonkman, G. A. D. Briggs, M. R. Castell and L. N. Kantorovich, Phys. Rev. B: Condens. Matter Mater. Phys., 2010, 81, 195412.

29 S. Yagai, K. Iwai, M. Yamauchi, T. Karatsu, A. Kitamura, S. Uemura, M. Morimoto, H. Wang and F. Würthner, Angew. Chem., Int. Ed., 2014, 53, 2602-2606. 
30 F.-Y. Hu, X.-M. Zhang, X.-C. Wang, S. Wang, H.-Q. Wang, W.-B. Duan, Q.-D. Zeng and C. Wang, ACS Appl. Mater. Interfaces, 2013, 5, 1583-1587.

31 M. P. Suh, Y. E. Cheon and E. Y. Lee, Coord. Chem. Rev., 2008, 252, 1007-1026.

32 F. Silly, J. Phys. Chem. C, 2012, 116, 10029-10032.

33 X. Zhang, Q. Zeng and C. Wang, RSC Adv., 2013, 3, 1135111366.

34 D. Trawny, P. Schlexer, K. Steenbergen, J. P. Rabe, B. Paulus and H.-U. Reissig, ChemPhysChem, 2015, 16, 949-953.

35 T. Nijs, F. J. Malzner, S. Fatayer, A. Wäckerlin, S. Nowakowska, E. C. Constable, C. E. Housecroft and T. A. Jung, Chem. Commun., 2015, 51, 12297-12300.

36 A. Wild, A. Winter, F. Schlütter and U. S. Schubert, Chem. Soc. Rev., 2011, 40, 1459-1511.

37 T. Earmme and S. A. Jenekhe, Adv. Funct. Mater., 2012, 22, 5126-5136.

38 M. Roos, D. Künzel, B. Uhl, H.-H. Huang, O. Brandao Alves, H. E. Hoster, A. Gross and R. J. Behm, J. Am. Chem. Soc., 2011, 133, 9208-9211.
39 C. Meier, K. Landfester and U. Ziener, J. Phys. Chem. C, 2009, 113, 1507-1514.

40 J. Zhang, B. Li, X. Cui, B. Wang, J. Yang and J. G. Hou, J. Am. Chem. Soc., 2009, 131, 5885-5890.

41 S. Wang, F. Zhao, S. Luo, Y. Geng, Q. Zeng and C. Wang, Phys. Chem. Chem. Phys., 2015, 17, 12350-12355.

42 T. Chen, W.-H. Yang, D. Wang and L.-J. Wan, Nat. Commun., 2013, 4, 1389.

43 F. Silly, J. Phys. Chem. C, 2013, 117, 20244-20249.

44 Y. Chin, D. Panduwinata, M. Sintic, T. J. Sum, N. S. Hush, M. J. Crossley and J. R. Reimers, J. Phys. Chem. Lett., 2011, 2, 62-66.

45 F. Silly, J. Microsc., 2009, 236, 211-218.

46 I. F. Perepichka and D. F. Perepichka, Handbook of Thiophene-Based Materials: Applications in Organic Electronics and Photonics, John Wiley \& Sons, 2009, vol. 2.

47 A. Mishra, C.-Q. Ma and P. Bäuerle, Chem. Rev., 2009, 109, 1141-1276. 